\title{
A CRIAÇÃO DE MATERIAL DE APOIO NA ATIVIDADE DE MEDIAÇÃO
}

\section{Creation of support material in mediation activity}

\section{Cristina Danielle Pinto Lobato}

Diretora de Projetos Especiais do Grupo I CAN. Mestranda em Bens Culturais e Projetos Sociais pelo CPDOC/FGV. Av. Jaime Poggi, n 99. Bloco 3, apt 1604. cristina_lobato@hotmail.com.

\section{Fernanda Fagundes Alves}

Instituto Solar do Sentir. Mestre em Educação pela Universidade de Brasília. Q 322 casa 14 Del Lago, Itapoã-DF. fernandafa@gmail.com.

\section{Resumo}

O desempenho da atividade de mediar conflitos é a arte de estar aberto ao outro, inteiramente presente, observando e ouvindo as narrativas das pessoas que sozinhas não conseguiram chegar a um consenso. Nesse caminho, podemos considerar alguns fundamentos significativos: a Comunicação Não-Violenta, sistematizada por Marshall Rosenberg, os nove degraus da escalada do conflito, apresentados por Glasl, bem como o modelo da Mediação Transformativa desenvolvido por Bush e Folger. E nesse exercício, o mediador pode fazer circular toda inspiração, observação, pesquisa e fundamentação teórica e prática de processos de transformação de conflitos criando materiais pedagógicos. Como foi o caso do livro recém lançado Ciranda do Ser de autoria de Cristina Lobato, advogada e mediadora. No presente artigo, serão apresentados alguns dos referenciais do livro e um resumo da obra.

Palavras-chave: Comunicação Não-Violenta. Escalada do Conflito. Mediação Transformativa. Material Pedagógico. Cultura de Diálogo.

\section{Abstract}

The practice of conflict mediation activity is the art of being open to the present, observing and listening to the narratives of people who could not reach a consensus. Following this line of thought, we have considered the following fundamental bases: Nonviolent Communication, systematized by Marshall Rosenberg, the nine escalation of the conflict, presented by Glasl, as well as the model of Transformative Mediation developed by Bush and Folger. And in this practice, the mediator can share all inspiration, observation, research, theoretical foundation, practice conflict transformation processes and create pedagogical materials. Such as the case of Ciranda do Ser, recently launched by Cristina Lobato, lawyer and mediator. This article will present some references from her book and a summary of the work.

Keywords: Nonviolent Communication. Conflict Escalation. Transformative Mediation. Educational Material. Culture of Dialogue.

\section{Sumário}

1. Introdução; 2. A comunicação não-violenta; 3. Os nove degraus da escalada do conflito; 4. Transformação das interações entre as pessoas em conflitos; 5 . Processo criativo da elaboração de material pedagógico; 6 . Conclusão; Referências 


\section{INTRODUÇÃO}

Você tem medo do quê? Muitas pessoas poderiam dizer ter medo de conflito, muito embora conforme Lederach (2012) aponta conflito possa ser entendido como algo comum nos relacionamentos humanos e desencadeadores de mudanças, bem como condição de crescimento, como na perspectiva proposta por Fayga Ostrower (1987, p. 28), para quem:

\footnotetext{
[...] criar representa uma intensificação do viver, um vivenciar-se no fazer; e, em vez de substituir a realidade, é a realidade; é uma realidade nova que adquire dimensões novas pelo fato de nos articularmos, em nós mesmo e perante nós mesmos, em níveis de consciência mais elevados e mais complexos.
}

Conflito é oportunidade e visto sob a perspectiva, tal como Gilbert (2015) aponta, do potencial criativo, pode ser o elemento para despertar a coragem para ampliar as capacidades para o autodesenvolvimento e ressignificar o processo de aprendizagem sobre a conflituosidade. Há "conflito social quando pelo menos um 'ator' (um partido, ou seja, uma pessoa, grupo etc.) vivencia a diferença de modo a sentir-se estorvado, pela ação do outro 'ator', para viver ou realizar as próprias imaginações, sentimentos ou propósitos” (GLASL, 2012. p.23).

De acordo com Glasl (2012) o desenvolvimento da autoafirmação diante dos conflitos é uma atitude que se encontra no meio do caminho entre o receio e a vontade de brigar, estando atrelada à consciência sobre os seus medos para agir de forma mais equilibrada.

Aquelas pessoas que têm receio de conflitos tendem à fuga e frequentemente colocam os interesses dos demais acima dos seus. Em sentido diametralmente oposto, aquelas cujo padrão é a vontade brigar, têm a tendência à agressão e a estarem centradas nos próprios interesses.

A autoafirmação, por sua vez, pressupõe a compreensão de que há efeitos positivos e negativos dos conflitos e de que quando nos conscientizamos dos nossos próprios medos, estes já não influenciam com a mesma força as nossas respostas automáticas. Isto implica, assim, o exercício do direito existencial de autoposicionamento: ser coerente consigo mesmo, com suas necessidades, interesses e valores, e agir considerando a própria responsabilidade pelos eventuais impactos das suas atitudes para os demais.

Nesse sentido, as seguintes suposições básicas são destacadas por Glasl (2012) na habilidade em conflitos:

Agressões são energia: eu as transformarei em energia positiva!

Conflitos ajudam a livrar-se de convencionalismos!

Diferenças são vitais; trabalhar as diferenças enriquecem a todos!

Essa tomada de consciência permite assumir o autocontrole das próprias atitudes para agir de forma conectada com as percepções sobre os resultados dos seus atos, cuidando das consequências das suas ações, lidando com as diferenças de modo criativo e construtivo. É entender a diferença entre ter um conflito e o conflito ter a você.

Nessa perspectiva a proposta da Comunicação Não-Violenta, desenvolvida por Marshall Rosenberg, contribui para tomada de consciência, que auxilia os envolvidos a tra- 
balharem a percepção da realidade em um processo de responsabilização em que cada participante pode se conectar com o que o afeta e ressignificar as ações que contribuem para o conflito.

Marshall Rosenberg (2006) afirma que "a violência é a expressão trágica de uma necessidade não atendida" e apresenta a Comunicação Não-Violenta como uma forma de nos expressarmos com mais honestidade e empatia, construindo interações com mais conexão por meio do reconhecimento dos sentimentos e das necessidades humanas universais.

Bush e Folger (2005) ao falarem sobre a Mediação Transformativa destacam a capacidade de transformação da qualidade da interação das pessoas em conflito, apoiando-as no fortalecimento pessoal (empowerment) e no reconhecimento (recognition), isto é, na autodeterminação dos envolvidos.

A autodeterminação está atrelada à autonomia e ao exercício das próprias escolhas sobre qual o caminho que deseja seguir diante da consciência sobre as infinitas possibilidades existentes no momento presente. É sentir a inteireza do ser diante da complexidade do conflito e tomar decisões de maneira informada, com olhar prospectivo, entendendo o processo de aprendizado com o passado.

Nesses termos, a Mediação Transformativa preserva a essência da mediação como método autocompositivo, ao considerar que o mediador é um facilitador que dá suporte para que as partes percebam seus padrões de comportamentos e possam construir novos parâmetros para uma comunicação com mais qualidade.

Assim, o mediador que compreende a importância do seu autodesenvolvimento desempenha a sua atividade de forma mais profissional, cuidando dos valores e dos princípios do processo da mediação, bem como da autodeterminação dos mediandos, que em muitas situações ou estão frágeis ou autocentrados diante de um conflito. O papel do mediador, consequentemente, é cuidar da interação entre as partes para que elas possam superar essa crise e co-criarem uma interação construtiva.

Nesse caminho, compartilhar suas experiências por meio da criação de materiais de apoio é uma forma de contribuir para o contínuo aperfeiçoamento da atividade de mediação, também para o fortalecimento da cultura de diálogo. Com o material de apoio é possível tornar a fundamentação teórico-conceitual da transformação de conflitos acessível a todos os participantes e assim, fortalecer a prática do mediador.

\section{A COMUNICAÇÃO NÃO-VIOLENTA}

A Comunicação Não-Violenta é uma forma de estar no mundo, de se relacionar consigo e com os demais seres. Foi sistematizada por Marshall Rosenberg, psicólogo norte-americano, após vários anos de sua experiência prática com Carl Rogers.

A abordagem terapêutica de Carl Rogers foi desenvolvida em torno da ideia de que existe um movimento natural para o próprio enriquecimento dentro de cada pessoa: uma tendência atualizante. Partindo dessa premissa, seu papel como terapeuta era criar um ambiente favorável ao desenvolvimento de a pessoa por meio de condições facilitadoras e 
de atitudes.

Uma das condições facilitadoras do Carl Rogers é a compreensão empática, que consiste em estar "sensível aos sentimentos e às reações pessoais que o cliente experiência a cada momento, quando pode apreendê-los 'de dentro' tal como o paciente os vê, e quando consegue comunicar com êxito alguma coisa dessa compreensão ao paciente" (ROGERS, 1961/1987, p. 66).

Marshall Rosenberg, considerando os fundamentos da compreensão empática, apresenta a Comunicação Não-Violenta como a linguagem da vida "uma forma de comunicação que nos leva a nos entregarmos de coração" (ROSENBERG, 2011, p.11). Isso porque em sua abordagem valoriza alta qualidade da comunicação que promoveria uma autêntica conexão para que a vontade espontânea de contribuir para transformação dos conflitos surja.

O termo "não-violência" é utilizado na mesma acepção de Mahatma Gandhi: estado compassivo quando a violência se afasta do coração.

São quatro os componentes didáticos da Comunicação Não-Violenta que facilitam um percurso para uma comunicação mais consciente expressada com honestidade e enriquecida pela empatia:

$1^{\circ}$. Observação - observar as situações como elas se apresentam, tomando consciência do que é julgamento do que é fato observável.

$2^{\circ}$. Sentimentos - reconhecer por meio da percepção atenta quais sentimentos, afetos, emoções e sensações estão presentes.

$3^{\circ}$. Necessidades - compreender quais valores, princípios e significados fundamentais podem estar sendo cuidados ou descuidados.

$4^{\circ}$. Pedido - expressar de forma honesta, simples e positiva aquilo que precisa para nutrir a sua vida.

A Comunicação Não-Violenta está baseada em três perspectivas: intrapessoal - você com você mesmo - interpessoal - vocês com as demais pessoas, e sistêmica - você em sociedade.

O primeiro ponto de conexão da Comunicação Não-Violenta com a mediação é na perspectiva intrapessoal: como profissional de gestão de conflitos, como estou cuidando de mim mesmo? Para apoiar pessoas é fundamental ter primeiro autoempatia, para que então seja possível oferecer ao outro espaço para a empatia.

Durante uma sessão de mediação, por sua vez, é possível que seja estimulada a Comunicação Não-Violenta na perspectiva interpessoal, com os mediandos e entre eles. A perspectiva sistêmica, por sua vez, está atrelada ao impacto da mudança de paradigma da mediação: da cultura de violência para a cultura de paz, de diálogo e de cooperação. Assim como, na construção de sistemas de apoio para que a partilha sobre os desafios desse caminhar possa ser um elemento de força para a construção das transformações sociais desejadas. 


\section{OS NOVE DEGRAUS DA ESCALADA DO CONFLITO}

Para Glasl (2012), enquanto as diferenças são objetivas e pessoais, há um conflito. Quando o conflito passa a ser sobre o conflito e sobre as suas soluções, o conflito tem a você. Nessa dinâmica da escalada do conflito ele destaca nove degraus: $1^{\circ}$ - endurecimento, $2^{\circ}$ - debate e polêmica, $3^{\circ}$ - ações em vez de palavras, $4^{\circ}$-imagens e coalizões, $5^{\circ}$ - perder a cara, $6^{\circ}$ - estratégia de ameaça, $7^{\circ}$ - ataques limitados de destruição, $8^{\circ}$ - desunião e $9^{\circ}$ juntos para o abismo.

O primeiro degrau é o endurecimento, momento em que os pontos de vistas se enrijecem e colidem, quando a comunicação deixa de ser fluida e surgem as reservas interiores. Nessa fase a prontidão para cooperação é maior do que a competição.

Por debate e polêmica entende-se a polarização em extremos com opiniões que parecem se excluírem mutuamente, com sucessivos argumentos e contra-argumentos. Consequentemente, há alternância entre cooperação e competição.

Quando no terceiro degrau há ações em vez de palavras, percebe-se uma desconfiança mútua entre as pessoas, que então se organizam em partidos, o que compromete a percepção sobre o outro. Assim, a competição é superior a competição. Até este ponto a autoajuda ainda é possível, isto é, as tentativas das próprias pessoas envolvidas no conflito ainda são eficazes.

Nesse sentido, uma mudança de cultura, da violência para a paz, perpassa por apoiar o desenvolvimento de "habilidades sociais no maior número possível de pessoas, para que em situações de conflitos elas pudessem praticar o máximo de autoajuda" (GLASL, 2012, p 11).

Já no degrau das imagens e coalizões há uma brutal distância entre os partidos, que já estão com percepções bastante comprometidas sobre o saber e as habilidades do outro. Portanto, a ajuda de pessoas próximas que não estejam envolvidas no conflito e tenham confiança das partes ou de profissionais faz-se necessária para que sejam compreendidas as percepções distorcidas.

O quinto degrau da escalada refere-se a perder a cara, ou seja, quando um dos partidos acredita que desvendou as reais intenções destrutivas do adversário, perdendo a crença no outro. Os aspectos do litígio passam ser sobre questões de princípios dos envolvidos, como, por exemplo, sobre religião, ideologia ou valores.

No sexto degrau a confrontação torna-se mais radical e violenta, pois diante da estratégia de ameaça há recíprocas exigências para que a outra parte ceda, com constrangimentos mútuos sobre a aplicação de sanções de acordo com a capacidade de sancionar que eventualmente possuam.

O degrau seguinte, ataques limitados de destruição, traduz-se nas ameaças concretizadas em ações, quando o outro é visto como categoria de coisa, desumanizado. Caminha-se lentamente em direção ao abismo quando as partes permanecem obstinadas com o conflito. 
No oitavo degrau, desunião, o desejo é pela destruição do outro, estando a coesão interior enfraquecida. Diante dessa situação, a atuação do mediador torna-se mais difícil, haja vista a necessidade de as partes estarem interessadas em colaborar para uma eventual solução.

Por fim, juntos para o abismo é ao nono degrau em que as pessoas já não conseguem mais enxergar outra forma de agir, sacrificando a própria autodestruição para a destruição do outro. Ainda assim, sempre há espaço para reflexão, o que exige dos envolvidos o autoencontro: sair do círculo vicioso e não saltar para o abismo, optando pela não-violência.

\section{TRANSFORMAÇÃO DAS INTERAÇÕES ENTRE AS PESSOAS EM CONFLITOS}

Entender essa dinâmica da escalada do conflito permite ao profissional que deseja atuar como mediador primeiro desenvolva a si mesmo, para então ter recursos internos que durante o processo de mediação possam ser utilizados para apoiar os mediandos no que eles desejarem. Compreender o contorno da sua atuação é fundamental para não invadir o espaço de autodeterminação das partes, cuidando da transformação da interação entre as pessoas em conflito nos limites que elas estejam dispostas a seguir.

A Mediação Transformativa, nessa perspectiva, considera que são as partes que detém a autonomia para aceitarem, seguirem e interromperem o processo, que contém um potencial único para transformar uma interação conflituosa e, como resultado, gerar mudança nos repertórios mentais dos envolvidos. É, portanto, o exercício da sua própria autodeterminação, é sentir a inteireza do ser diante da complexidade do conflito e tomar decisões de maneira informada, com olhar prospectivo, entendendo o processo de aprendizado com o passado.

O potencial transformativo decorre da profunda conexão do mediador com os mediandos, favorecendo a regeneração de duas importantes dinâmicas: o empoderamento e o reconhecimento. $\mathrm{O}$ empoderamento entendido como a compreensão sobre o senso de valor e força na própria capacidade de tomar decisões, enquanto o reconhecimento é ter empatia pela situação do outro.

Quando uma das partes está fragilizada, tende a apresentar comportamentos que denotam insegurança, confusão, medo, desorganização e incerteza, sendo, assim, necessário o seu empoderamento. Por outro lado, quando uma pessoa em conflito está autocentrada, adota posturas autoprotetivas, defensivas, hostis, estando fechada para o outro, sendo necessário o reconhecimento de outros pontos de vista.

Nesse modelo de mediação, o mediador é um terceiro sem interesse ou diretividade na condução dos resultados do processo, pois atua de acordo com a perspectiva trazida pelos mediandos e mantém uma contínua conexão com eles. Em razão disso, não se estabelecer regras para a dinâmica do processo de comunicação, trabalha-se com o diálogo da forma que ele se apresenta, sem introduzir qualquer componente artificial na conversa.

É entender o mediador como colaborador no que for útil para as partes, e enquanto assim for, pois são elas que controlam o processo: desde a adesão à mediação, à continui- 
dade e ao acordo. As técnicas utilizadas visam ao estímulo do fluxo contínuo da fala para o sucessivo aprofundamento das questões trazidas. Portanto, a conexão é um dever do mediador, o que propicia um estímulo à reflexão sobre os comportamentos dos mediandos, quando eles tomam consciência de suas próprias dinâmicas relacionais.

O papel do mediador, consequentemente, é cuidar da interação entre as partes para que elas possam superar essa crise e co-criarem uma convivência construtiva. Desse modo, é oferecido um novo paradigma: o mediador colabora com o que, como e para o que quiserem as partes. O centro do processo é olhar para as pessoas, estimulando o seu potencial e os elementos de mudanças para uma interação diferente, com escuta plena, para que o diálogo seja transformador.

Segundo John Paul Lederach (2012), a transformação de conflitos é mais do que um conjunto de técnicas específicas; é um modo de olhar e ao mesmo tempo enxergar. Tanto para olhar como para enxergar precisamos de lentes. Portanto, a transformação de conflitos sugere um conjunto de lentes pelas quais conseguiremos enxergar o conflito social.

O autor sugere o uso das lentes da transformação de conflitos para enxergar a situação imediata, os padrões subjacentes e contexto, bem como a estrutura conceitual das relações, ou seja, "criar uma estrutura capaz de tratar do conteúdo, do contexto e da estrutura do relacionamento" (LEDERACH, 2012, p. 24).

\section{PROCESSO CRIATIVO DA ELABORAÇÃO DE MATERIAL PEDAGÓGICO}

Os materiais de apoio pedagógicos são recursos potentes para serem utilizados tanto nas sessões de mediação, quanto em momentos de formação e sensibilização sobre a mediação.

Muito está sendo produzido sobre o tema da mediação de conflitos, contribuindo para o contínuo aperfeiçoamento dos profissionais e o compartilhamento das experiências favorece a melhoria da qualidade das atividades desempenhadas.

O livro Ciranda do SER lançado no mês de outubro de 2018 pela autora Cristina Lobato representa o esforço em traduzir de forma lúdica elementos da Comunicação Não-Violenta tais como o propósito, o processo e os desdobramentos. Tudo isso em uma linguagem acessível para crianças e contribuir para a disseminação do tema em diferentes contextos.O livro surgiu de uma música, criada pela autora, apresenta um formato interativo, com questões que dialogam com a realidade dos leitores e ainda possibilita aos mesmos a oportunidade de colorirem as ilustrações.

O formato do livro foi pensado de forma a favorecer a autodeterminação com a construção de autonomias a partir de uma perspectiva empoderadora, trazendo uma reflexão que favorece a conexão com as próprias escolhas e também o reconhecimento numa perspectiva de construção de empatia com o outro.

Pode ser usado tanto na formação para desenvolvimento de habilidades para lidar com o conflito ou mesmo durante o processo de mediação, especialmente, quando há uma 
escalada aprofundada do conflito e as partes estão profundamente impactadas. Isso porque o ato de parar de falar sobre as circunstâncias em si para ler e entender a intenção e o processo seguido na mediação inspirado pela Comunicação Não-Violenta é possível criar um ambiente seguro de abertura do espaço de autodeterminação dos mediados, favorecendo a tomada de decisões que promova a transformação de interações e uma nova mentalidade para lidar com os motivadores do conflito.

Inicialmente pensado como um recurso de interação dos adultos com as crianças, o livro por utilizar metáforas, ter uma melodia na sua construção e desenhos para colorir, permite também que o adulto sozinho acesse sua criança interior.

Foram realizadas atividades com adultos nas Casas da Família do Tribunal de Justiça do Estado do Rio de Janeiro, nos Fóruns Regionais de Santa Cruz, Leopoldina e Bangu, assim como nos Centros Judiciários de Solução de Conflitos e Cidadania dos Fóruns Regionais de Jacarepaguá e de Nova Iguaçu. Nessas oportunidades foi possível identificar o impacto da reflexão sobre memórias e sonhos da época de criança no adulto que hoje desempenha a atividade de mediador, educador ou servidor público.

Criou-se, assim, um espaço de leveza para possibilitar que o adulto pudesse olhar para o passado e ressignificar aquilo que viveu ou compreender seus padrões comportamentais de hoje em perspectiva com a sua criança.

Assim, trazer o lúdico da ciranda, esse tipo de dança e música característica pela formação de uma grande roda, permite um momento de união, de brincadeira e de alegria. Tudo isso favorecendo uma conexão tão fundamental para transformação de conflitos.

Ademais, na nossa educação não é comum falarmos sobre as nossas emoções, afetos ou sentimentos, então esse livro chega com essa abertura para uma auto-observação.

Por exemplo, você saberia dizer como está se sentindo agora? Segue uma lista com vocabulário para apoiar você nessa missão: à vontade, alegre, alívio, angústia, animado(a), encantado(a), apatia, aversão, repulsa, ciúme, concentrado(a), confuso(a), culpa, curioso(a), empolgado(a), desapontamento, pesar, desprezo, nojo, dor , euforia, impotência, medo, preocupado(a), raiva, fúria sereno(a), sobrecarregado(a), solidão, tristeza, vergonha, vibrante.

\section{CONCLUSÃO}

Um conflito atinge a totalidade em nós, nossos sentimentos e pensamentos. Conflitos exigem de nós tudo o que temos para oferecer" (GALTUNG, 2006, p.13), então o uso e criação de materiais de apoio pelos mediadores repercute na qualidade do processo ao compreender o seu papel de dar o suporte necessário às pessoas nesse momento de crise.

A Comunicação Não-Violenta "[...] nos ajuda a nos ligarmos uns aos outros e a nós mesmos, possibilitando que nossa compaixão natural floresça" (ROSENBERG, 2011, p.32), abrindo espaço para os sentimentos e as necessidades nas interações humanas, tornando-as mais honestas e empáticas.

Vimos que o livro Ciranda do SER fortalece esse espaço de interação, tanto para com 
a pessoa sua trajetória pessoal e respostas aos conflitos quanto no nível da interação com as pessoas, num processo que favorece a cultura da paz. Pode ser usado pelo mediador em contribuindo para a transformação dos conflitos a nível intrapessoal, interpessoal e sistêmico.

Primeiramente, entendendo seus próprios limites na atuação: como a questão toca o seu ser? Há aspectos sensíveis que precisam ser considerados para que não haja interferência das histórias pessoais?

Especialmente pode ser usando em diversos momentos do degrau da escalada do conflito as pessoas se encontram: $1^{\circ}$ - endurecimento; $2^{\circ}$ - debate e polêmica; $3^{\circ}$ - ações em vez de palavras; $4^{\circ}$ - imagens e coalizões; $5^{\circ}$ - perder a cara; $6^{\circ}$ - estratégia de ameaça, $7^{\circ}$ ataques limitados de destruição, $8^{\circ}$ - desunião e $9^{\circ}$ - juntos para o abismo.

Assumindo que cada estágio demanda uma forma de atuação diferente, na medida em que o grau de cooperação reduz a cada degrau, em contrapartida, a competição aumenta. Em cada estágio o enfoque da leitura pode ser dado de forma diferente. Sobretudo considerando que mediar estar imbuído do desejo de co-criar novas interação possíveis.

Na Mediação Transformativa, o mediador cuida para que sua atuação não introduza elementos artificiais na dinâmica de comunicação entre as pessoas em conflito, não estipula regras para o diálogo. Assim, os princípios da não diretividade e da autodeterminação das partes são resguardados durante todo o processo.

Há, nessa abordagem, uma conexão intensa entre o mediador e as partes. Nesse sentido, Daniel Goleman (2014) afirma que "uma relação empática exige atenção conjunta - foco mútuo". Considerar essa perspectiva na mediação é trazer as partes para o momento presente, sem desconsiderar o que houve no passado, mas com olhar voltado para a reflexão sobre como estão agora e como desejam estar no futuro.

Essa visão é um convite ao diálogo e à aprendizagem por meio do compartilhamento de diferentes pontos de vista, considerando a mediação como um processo no qual as pessoas podem desenvolver suas habilidades e competências para apreciarem o melhor em si e do outro. Entende-se o diálogo na concepção de David Bohm, para quem "o diálogo é mais uma participação, na qual não jogamos uns contra os outros, mas com cada um deles".

O mediador, portanto, é responsável por assegurar um ambiente seguro para a conversa, assim como por estabelecer confiança com os mediandos para que eles possam falar sobre suas questões na profundidade e no tempo que desejarem.

Para tanto, o autodesenvolvimento é um caminho contínuo, não há destino certo, é no cotidiano que o ser humano se faz e refaz, aprendendo, amando, ressignificando, transformando. Ser mediador também é um eterno reinventar, cuidado das relações, das necessidades, dos valores e dos sentimentos das pessoas que estão em conflito.

Conforme expõem Goleman e Senge, é ter foco interno, no outro e também externo, ou seja, um triplo foco, considerando o seu ser, os outros seres e o sistema no qual todos estão inseridos. Esse olhar é mais amplo, pressupõe uma percepção da complexidade das 
relações, investindo diariamente no processo pessoal de aperfeiçoamento da autoconsciência, da autogestão, da empatia e de habilidades sociais.

Assim, a elaboração de matérias pedagógicos e o compartilhamento de experiências permite que os profissionais estejam em considerando também o autocuidado e construindo sistemas de apoio. É um constante vir a ser mediador, ou quem sabe, mediar o amor.

\section{REFERÊNCIAS}

BUSH, Robert A. Baruch; FOLGER, Joseph P. The promise of mediation: the transformative approach to conflict. São Francisco: Jossey-Bay, 2005. p.13.

GALTUNG, Johan. Transcender e transformar: uma mudança ao trabalho de conflitos. São Paulo: Palas Athena, 2006. p.13.

GILBERT, Elizabeth. Grande Magia: vida criativa sem medo. Rio de Janeiro: Objetiva, 2015. p.15

GLASL, Friedrich. Autoajuda em conflitos: uma metodologia para reconhecimento e soluções de conflitos em organizações. São Paulo: Antroposófica: ADIGO, 2012. p.23.

GOLEMAN, Daniel. Foco: atenção e seu papel fundamental para o sucesso. Rio de Janeiro: Objetiva, 2014.

LEDERACH, John Paul. Transformação de Conflitos. São Paulo: Palas Athena, 2012. p. 17.

OSTROWER, Fayga. Criatividade e processo de criação. Petrópolis: Vozes, 1987. p. 28.

ROGERS, Carl.Tornar-se pessoa. São Paulo: Martins Fontes, 1987.

ROSENBERG, Marshall B. Comunicação não-violência: técnicas para aprimorar relacionamentos pessoais e profissionais. São Paulo: Ágora, 2006.

Recebido em: 27/11/2018

Aceito em: 02/12/2018 